\title{
FOTOS Y VOCES EN LA CIUDAD. LA MARGINALIDAD EN LA POESIA CHILENA DEL 2000 DESDE UNA PERSPECTIVA INTERMEDIAL *
}

\section{Martina Bortignon**}

\section{Resumen}

Este artículo pretende explorar desde una óptica intermedial los poemarios sobre marginalidad urbana Compro fierro (2007) de Juan Carreño y Gran Avenida (2004) y Aire quemado (2009) de Gladys González. A partir de categorías teóricas como leyenda, voyeurismo y dispositivo colectivo de enunciación, y de la analogía con las redes sociales y otros usos de internet, se estudiará la vinculación de la palabra poética con otras artes: a saber, la fotografía y el fotograma en Gladys González, el registro sonoro y el documental en Juan Carreño. La topografía marginal que estos dos autores construyen estriba en el protagonismo del cuerpo y de la voz de los ciudadanos, apelando a tejer una trama de sentido y sentidos que involucre al lector.

Palabras clave: Intermedialidad, poesía, marginalidad, Juan Carreño, Gladys González.

\section{Pictures AND VOICES IN THE City. An INTERMedial PERSPECTIVE ON MARGINALITY IN THE CHILEAN POETRY OF THE 2000s}

\begin{abstract}
This essay aims at exploring from an intermedial perspective Compro fierro (2007) by Juan Carreño, and Gran Avenida (2004) y Aire quemado (2009) by Gladys González, poetry works about urban marginality. With the help of concepts such as legend, voyeurism, and collective assemblage of enunciation, and of the analogy with social networks and other uses of internet, relation between poetic word and other arts will be studied; i.e. photography and film still in relation to Gladys González, audio record and video-documentary in relation to Juan Carreño. The marginal topography that these two poets create enhance the role of citizens' body and voice, invoking the weaving of a weft of meaning and perceptions in which the reader participate.
\end{abstract}

Keywords: Intermediality, poetry, marginality, Juan Carreño, Gladys González.

Recibido: 11-08-2015

Aceptado: 25-08-2015

* $\quad$ Este artículo se inscribe en el Proyecto de Investigación Postdoctoral CONICYT Fondecyt n. 3140423 "La palabra sensible. Sensaciones y lenguaje poético en obras chilenas e italianas contemporáneas" del cual soy Investigadora Responsable. Una primera versión del mismo fue presentada como ponencia en el congreso III Jornadas de Literatura General y Comparada, 1-2 de Octubre de 2013, Universidad de Chile, Santiago.

** Italiana, Doctora en literatura (U. Ca' Foscari Venezia, P. Universidad Católica de Chile). Académica de la Universidad Adolfo Ibáñez, P. Universidad Católica de Chile, Santiago, Chile.

martina.bortignon@uai.cl 


\section{Una polémica interesante}

En una reciente conversación pública sobre la poesía joven en Chile, uno de los críticos invitados mencionó brevemente la poesía de Juan Carreño, nacido en 1986, y declaró su juicio desfavorable con cierto ensañamiento. En su comentario, destacó cómo los poemas, que reconstruyen situaciones de marginalidad en las comunas desfavorecidas de Santiago reproduciendo el habla sociolécticamente marcada de sus habitantes, se harían cómplices de la propagación de estereotipos en lugar de generar una reflexión crítica. Comparó, también, la retórica elegida por el poeta con la exacerbación con que los efectos visuales en el programa de televisión chilena Atrapados por la realidad mediatizan hechos de crónica urbana, como los robos con asalto o el consumo de drogas, contribuyendo a que el imaginario colectivo asocie los sectores sociales marginados con la delincuencia. También el diálogo final con el público resultó imprevisiblemente monopolizado por una polémica sobre la poesía de Carreño. En medio de los animados comentarios en favor o en defensa de la propuesta estética del autor, uno de los críticos corrigió el juicio negativo del colega adscribiendo la poética de Carreño al cine social FECISO, que lleva unos años dedicándose a formar gratuitamente a aficionados que eligen el medio fílmico para contar su entorno sociourbano a menudo difícil.

Esta anécdota, más allá de su relativo valor documental sobre las polémicas de crítica literaria de los últimos años en Santiago de Chile, es significativa en tanto se pueden sacar de ella dos reflexiones fundamentales para lo que va a ser el objeto del presente escrito. Por una parte, el hecho de que el debate se concentrara únicamente en un autor que había elegido el ambiente degradado de la periferia urbana como ámbito de búsqueda poética, frente a la amplia variedad de cuestiones que fueron planteadas por los panelistas sobre la poesía joven chilena, delata el poder simbólico que tiene el significante de la marginalidad social en el discurso artístico y crítico contemporáneo. El grado de emotividad, aunque contenida, con que se desarrolló la discusión, denuncia el hecho de que tal significante llega muy fácilmente a ser terreno de disputa. Me aventuro a especular que la marginalidad puede volverse el locus del deseo implícito, por parte de artistas e intelectuales, por relatar, cuidar y dominar discursivamente una parte de lo real. La marginalidad funciona, en este caso, como "significante performativo" (Butler 1993): un término 
que construye desde la discursividad el referente al que se refiere canalizando las inversiones simbólicas y libidinales de los sujetos que lo nombran. En consecuencia, el discurso que se va tejiendo sobre una realidad y sus protagonistas que, en la mayoría de los casos, se encuentran muy alejados de la experiencia vivencial de quienes participan en los eventos culturales en las librerías del centro, nos informa más sobre las proyecciones de los intelectuales y del público letrado que sobre la situación real a la que este mismo discurso alude.

Por otra parte, es llamativo el hecho de que por lo menos dos críticos, desde posiciones y valoraciones divergentes, acudieron a una comparación con una práctica cultural o artística diferente a la literaria -el formato televisivo y el cine documental- para transmitir al público no especializado su opinión sobre la obra poética. La discusión crítica contemporánea demuestra, así, haber asimilado y convertido a sus fines, incluso en contextos no estrictamente académicos, una práctica ya sólidamente asentada en las artes: la permeabilidad entre diferentes medios y lenguajes artísticos. La categoría de la intermedialidad, en otras palabras, no se limita ya a ser una herramienta de elaboración estética sino que se ha vuelto un horizonte epistémico y hermenéutico, dentro del cual la acepción digital y comunicacional de la palabra "media", con su referencia a la época 2.0 de conexión permanente y permanente interacción entre los usuarios, es un elemento insoslayable del debate más reciente. En una ecología del presente que se dibuja a partir de los rasgos de dialogismo, relación, mutualidad, cabalmente resumidos en el prefijo "inter", la intermedialidad sería, pues, una condición originaria, la posibilidad misma de existencia de creaciones artístico-culturales y de su recepción crítica (López-Varela 2011).

En estas páginas, pues, me propongo estudiar, desde una óptica intermedial y con un ojo a las implicaciones libidinales y simbólicas para el público letrado, los poemarios publicados en la década del 2000 por dos poetas chilenos: Compro fierro (2007) del ya citado Juan Carreño, y Gran Avenida (2004) y Aire quemado (2009) de Gladys González. Lo que me interesa destacar es que su exploración de aspectos de la marginalidad urbana santiaguina a principios del nuevo milenio se efectúa a través de una operación estética que lleva al ámbito poético elementos pertenecientes a medios artísticos distintos: en concreto, la fotografía-fotograma en Gladys González y el registro sonoro en Juan 
Carreño. La exploración de este primer aspecto de la intermedialidad, que afecta la poesía sin modificar su especificidad de palabra escrita, se complementará con la indagación sobre el vínculo que los poetas establecen entre la poesía y, respectivamente, la imagen fotográfica real y la grabación de voces real. En el caso de González, me adentraré en una lectura crítica que articula el texto poético con la iconicidad del paratexto, o sea las fotos que aparecen en las cubiertas de sus poemarios y que retratan a la poeta en entornos marginales. Posteriormente, vincularé la poesía de Carreño con su corto Santo Tomás. Entre Bahía Catalina y La Serena, entre la iglesia y loh pacoh (2011) con que el artista responde, desde la estética cinematográfica, a las mismas inquietudes sobre la oralidad que están a raíz de sus poemas.

Estas operaciones de hibridización artística dejan vislumbrar por lo menos tres aspectos novedosos. En primer lugar, está la atención por el dato sensible, con una natural prominencia, en las dos propuestas, de los sentidos de la vista y del oído. Las escenas de marginalidad urbana que emergen de estos procedimientos creativos conforman una ciudad "percibida", en la cual el lector queda involucrado sensorialmente, ya que la elaboración del mensaje excede la palabra poética tout-court. Esta complejidad se debe también a la superposición inevitable de la respuesta estética del lector de poesía con la del receptor de otros lenguajes artísticos. En segundo lugar, tales propuestas no son pensables, en el contexto del nuevo milenio, sino en relación con las prácticas vinculadas con las nuevas tecnologías. La perspectiva intermedial permite asociar con la lógica de Facebook el dejo exhibicionista con que la protagonista de los poemas de González nos hace guiño desde la página, mientras que la cercanía casi obsesiva a la individualidad de las voces de los habitantes de La Pintana, en Carreño, recuerda los videos caseros subidos por los usuarios en YouTube. Esto nos conduce al tercer punto, que es el retorno del sujeto al centro del interés artístico, un sujeto rehabilitado y explorado tanto en su dimensión personal como en la dinámica de la comunidad, sea ésta real o virtual. La topografía marginal que estos dos jóvenes autores construyen estriba, efectivamente, en el protagonismo del cuerpo o de la voz de los ciudadanos por sobre las visiones de conjunto de la urbanística, y apelan a tejer una trama de sentido y sentidos que involucre al ciudadano que se encuentra al otro lado de la página, de la foto o de la pantalla. 


\section{Una rebelde vintage-punk: la leyenda de Gladys González}

Con el poemario Gran Avenida, Gladys González inaugura la leyenda de una joven rebelde que escoge conscientemente la periferia -y específicamente Gran Avenida, una zona emblemática y connotada en un sentido marginal de la zona sur de Santiago- para sus andanzas nocturnas entre bares de mala muerte, paraderos anónimos y moteles escuálidos. Al jugar con la dependencia de amores violentos, alcohol, drogas y poesía, la protagonista de los poemas parece querer ponerse a prueba, cruzar constantemente el límite. La nota a pie de página del poema "Tul", referida al verso que recita "mi casita de la zona sur", especifica: "(1) Los amigos dicen que soy / una tonta / Qué quieres experimentar / Yo les digo que soy un tubo de / ensayo / Me miran y mueven la cabeza / Saben que voy a sufrir / Yo les creo todo" (38). En el siguiente poemario, Aire quemado, la casita de la zona sur se convierte de pied-à-terre para noches de nomadismo febril a prisión escuálida. La leyenda de la transgresión evoluciona a leyenda del desastre: la sujeto acepta apáticamente la existencia sin perspectivas a la que la han llevado sus arrebatos juveniles. Ahora ella yace en una cama, apilando colillas y horas vacías, contemplando en un espejo "[...] la destrucción / con la ternura / de los ojos de un novillo / en el minuto / en que es degollado en un matadero" (25).

Considero que la noción de "leyenda" refleja apropiadamente el tipo de operación poética que las dos obras fundamentan. En primer lugar, si pensamos en la leyenda como una construcción narrativo-simbólica sobre un hecho o una persona que fusiona elementos procedentes de la realidad con elementos procedentes del imaginario colectivo, podemos entender la escritura de Gladys González en los términos de construcción de una leyenda biográfico-poética personal que combina la dimensión de la producción textual con las resonancias casi míticas de una vivencia en una suerte de margen hipster, de malditismo y desviación elegida. Efectivamente, la explícita superposición de diferentes niveles enunciativos en los aspectos textuales y paratextuales que componen las obras apunta hacia una identificación arte-vida. Tales aspectos son: las declaraciones a la prensa en ocasión del lanzamiento de los libros, las fotos de portada que retratan a la poeta, la nota biográfica en la solapa, el contenido y la retórica de los poemas. Se genera, de esta forma, la 
impresión de que el nivel del autor ${ }^{1}$ colapsa en el del personaje autoral ${ }^{2}$ y éste en el nivel del locutor ${ }^{3}$. Es decir, el texto poético se propone como un recuento de "una vida no ejemplar", donde su autor coincidiría con el personaje que toma la palabra en el poema. Una declaración de Gladys González, en ocasión de una entrevista, vuelve patente esta anhelada fusión entre funciones textuales y vivencia real: "me señalo como mi propio poema por lo que hago de mi vida un gran poema y después pierdo la noción de eso. Como consecuencia, a veces mi vida se vuelve un poco turbulenta. La consigna arte y vida o, en este caso, arte y poema, es indeclinable" (cit. en González Barnet s/f: s/p).

En segundo lugar, leyenda significa literalmente, siguiendo su étimo latino legenda, "las cosas que hay que leer", a la luz, en nuestro caso, de una determinada clave interpretativa. El citado efecto de autobiografía "legendaria" se construye necesariamente a partir de una cuidadosa selección de determinados rasgos por sobre otros, en un juego que encubre y descubre a la vez la ficción producida por el texto. "Representar" sería propiamente un "presentar", un "exponer a la vista". Se evidencia así un desfase entre esos mismos niveles enunciativos que se pretendía comprimir en la verosimilitud autobiográfica: la leyenda se vuelve disfraz, evidencia de una pose; la protagonista-autora de los poemas se transforma en una persona -"máscara" en latín- que está posando en un estudio fotográfico. Silvia Molloy (1994) reflexiona sobre el concepto semiótico de la pose, realzando el juego entre homogeneidad e interrupción que el posar inaugura con respecto al referente aludido: “la pose [representa] (ahora en el sentido teatral del término) pero como impostura significante. Dicho más simplemente: la pose dice que es algo; pero decir que se es ese algo es posar, es decir, no serlo." (134). La dimensión fotográfica implícita en el concepto de "pose" remite al universo de la visualidad, allá donde la palabra poética se convierte en

1 Sujeto biográfico que se inserta en tanto productor de cultura en coordinadas histórico-culturales determinadas y en un campo literario determinado.

2 Alter ego ficcional-biográfico que el poeta proyecta al borde del enunciado poético, para que el lector pueda identificarlo como productor de la obra según unos rasgos específicos que influyen en la interpretación general de la misma. Por ejemplo, el personaje autoral se puede presentar como homosexual, mapuche, punk, más allá de la efectiva o completa adscripción del autor a estas categorías en su vida privada.

3 La instancia que dice "yo" en el enunciado poético, esto es, el personaje que habla en el poema. Para una profundización sobre estas y otras distinciones desde el punto de vista enunciativo, me permito remitir a mi artículo "El sujeto enunciativo en poesía. Propuesta de un modelo de estudio", Gramma 51 (2013), Universidad del Salvador, Buenos Aires. 40-57. 
imagen fotográfica. Con la pose fotográfica evocada en el lenguaje, nos encontramos en una situación de cruce entre medios que ha sido definida por la teórica Irina Rajewsky como "referencia intermedial":

here it is by definition just one medium-the referencing medium (as opposed to the medium referred to)-that is materially present. Rather than combining different medial forms of articulation, the given media-product thematizes, evokes, or imitates elements or structures of another, conventionally distinct medium through the use of its own media-specific means. (53)

Llama la atención que, en González, la imitación de las herramientas retóricas y de los efectos estéticos de la fotografía se entrelaza con la ya mentada dimensión "legendaria". El poema "Swing" es un buen ejemplo de ello: "Dua, dua, dua / Ella Fitzgerald/ los ojitos de sueño / americano / sacudiéndose / en el Savoy / / Dua, dua, dua / Gladys González / los ojitos de heroína / sacudiéndose / en la Habana Club / / oculta los colores / del fracaso / en el mismo swing oscuro" (2004: 12). El poema se propone a la lectura-visión como si se tratara de un fotograma de una película de los años 40. Un mismo patrón sintáctico, al replicarse en las dos primeras estrofas, superpone la imagen de las dos mujeres en una sola visión borrosa cargada de sensualidad. El juego óptico del fundido, típico tanto del cine como de la fotografía, hace que los bordes y las masas de los cuerpos de las dos mujeres se desdibujen como en el efecto flou de las películas en blanco y negro de la época. En particular, la analogía instaurada, en el presente del poema, entre una joven Ella Fitzgerald ${ }^{4}$, futura leyenda del jazz americano, y la poeta Gladys González, con un futuro artístico todo por descubrir, transfiere el halo mítico asociado con la primera a la segunda. Simultáneamente, el lector percibe el humo de cigarro adensándose en el ambiente, el embotamiento producido por el cansancio y el alcohol, el brillo de las pallettes de los vestidos y de las trompetas de las big bands, el desenfreno

4 Junto con la alusión al "sueño / americano", la mención al Savoy -una de las ballroom más populares de Harlem, escenario privilegiado del Lindy Hop y grandes bandas jazz desde los años 20 hasta los años 50- permite aventurar que el texto se refiere al inicio de la carrera de Ella Fitzgerald, en 1934, cuando la artista empezó a cantar en la band de Chick Webb. Ese mismo año Edgar Sampson compuso la canción "Stompin' at the Savoy", que fue interpretada por la misma Ella Fitzgerald y Luis Armstrong en 1956. 
de los cuerpos en el swing, todos elementos que el poema, en su fulminante concisión, introduce subrepticiamente a nivel perceptivo sin necesidad de nombrarlos. Gracias a la atmósfera perceptiva recreada en el poema, el lector-espectador experimenta varios sentimientos a la vez: la veneración debida a las estrellas de la música, el recuerdo estetizante de los fastos del jazz americano y, eventualmente, la tentación de ponerse en una posición de dominio con respecto a la protagonista; el hecho de que ella esté posiblemente drogada y su vocación al fracaso la hacen débil y "aprovechable". Sin embargo, la ambigüedad estudiada de la palabra "sueño" (producida por el enjambement que atrasa la atribución del sentido concreto por sobre el simbólico) y de la palabra "heroína" (por la homografía entre el término que se refiere a la droga y el femenino de héroe) inscribe una grieta en la pátina vintage de la imagen. También el cambio de locación -del mítico Savoy newyorkino al Habana Club, local intrascendente para bailar en Santiago-introduce una nota disonante de ironía. El lector se pregunta si acaso el texto no le pasó una mala jugada, al despistarlo con una asociación tan evidente entre locutora y figura de leyenda. Ya no tan cómodo en su posición privilegiada respecto a la escena, confundido por la mise en abyme de las poses, el lector percibe el doble y triple fondo en la construcción de la imagen y pierde su poder sobre la supuesta "heroína" del margen.

Otros poemas, los cuales no exhiben tan directamente (es decir, a través de la mención del nombre propio) la insidiosa ecuación entre autora y locutora, empujan hasta la exceso la faceta autodestructiva y la vocación a la marginalidad del personaje poético. Su rebeldía punk la acerca peligrosamente a tachas y púas ("Toda yo alambrada / recogida por los muslos / la carne floreciendo por las / púas...", (2004: 33)) y la atrae en situaciones que amenazan su incolumidad ("...hubo noches / en las que me golpearon tanto / que caí al suelo / con un diente destrozado / y la cabeza rota / como una granada hirviendo..." (2010: 12)). La posición de dominio del lector no es puesta en discusión sino que es exasperada hasta el voyeurismo, como en el poema "Colirio" (2010: 14), donde la espectacularización de la herida queda sancionada en la pose agachada y vulnerable de una “...una perfecta / y experimentada / zurcidora" que decora con rimmel los bordes del corte. La perseverancia de la protagonista poética en infligirse las posiciones más retorcidas y degradantes exhibiéndolas bajo una luz inquisidora recuerda los sujetos 
sufrientes de Egon Schiele o Francis Bacon; llega incluso, en algunos casos, a referirse a la iconografía, declinada al femenino, del Ecce homo, la presentación pública del Cristo golpeado y flagelado ("Naturaleza muerta" (2010: 12)). En cada uno de estos casos, se enfatiza el lado visual del texto poético, la consagración de la pose del personaje en la inmovilidad de la fotografía o del fotograma. Comparados con el poema analizado al principio, estos otros textos demuestran que, cuando la coincidencia entre las posiciones enunciativas se limita al uso de verbos y pronombres en primera persona, se hace más intensa la ilusión de autobiografismo; por el contrario, cuando la coincidencia es más patente, por ejemplo con la referencia al nombre propio de la autora, se introduce una duda en el lector con respecto a la veracidad de esta superposición.

Una instancia peculiar donde se evidencia macroscópicamente el desajuste intrínseco de la "leyenda" es la foto de cubierta de las obras. Aquí se aplica otro aspecto de la intermedialidad detectado por Rajewsky, a saber el diálogo o combinación entre dos formas mediales, "each present in their own materiality and contribut[ing] to the constitution and signification of the entire product in their own specific way. Thus, for this category, intermediality is a communicative-semiotic concept, based on the combination of at least two medial forms of articulation" (52). En el caso que nos ocupa, foto de cubierta y textos como fotos o fotogramas dialogan inter-semióticamente y se reflejan la una en los otros, llevando la leyenda de la niña rebelde a un nuevo, más desafiante nivel. En concreto, la imagen fotográfica real se vuelve el punctum sustraído y desfachatado hacia el cual convergen las fotos verbales que son los poemas, el ícono definitivo que condensa visualmente el sentido del poemario correspondiente.

En cada una de las dos fotos, la autora en figura y persona se exhibe en poses cuidadosamente estudiadas e insertadas en entornos urbanos desamparados o marginales. La foto de cubierta de Gran Avenida es una imagen nocturna que retrata a la artista sentada en el bandejón central de susodicha carretera, una arteria que se adentra en la periferia sur de Santiago. La chica, iluminada por la luz amarilla de los faroles y por los focos de los autos, lleva un vestido corto y negro, típica prenda para una salida de diversión. Su posición un tanto abandonada denota que la noche de fiesta y borrachera está por llegar a su fin. Como lo confirman los poemas del libro, la foto alude a una vida de excesos y nomadismo. 
La foto de cubierta del libro siguiente, Aire quemado, ha sido tomada sobre el fondo de un caserío parcialmente derruido y cubierto de graffitis, en medio de cúmulos de escombros y basura. La poeta ahora lleva ropa diurna, y expone la cara al sol, sin mirar directamente hacia el objetivo. La presencia de elementos arquitectónicos manifiesta una tendencia al asentamiento (aunque precario) y la resignación a una vida sin perspectivas que vendrían a ser las dominantes temáticas del segundo libro. La elección de la autora de poner fotos de sí misma habla de su aparente voluntad de apropiarse, mediante la figura autoral, de su obra desde el paratexto, subrayando la existencia de un pretendido lazo entre vida y arte, entre biografía y escritura. El hecho de que esta equivalencia quede establecida en un lugar tan estratégico como la portada, hace que la naturalidad de la circulación e intercambiabilidad de elementos entre los dos planos sea denunciada como ficticia, construida, justamente, como en un estudio fotográfico. Como ya se vio anteriormente, también acá la estrategia de lo artificial de la pose termina por denunciar la verosimilitud como ficticia.

Para una cabal comprensión de las implicancia de esta operación retórica, resulta productivo establecer un paralelo entre esta solución estética y la que subyace a la obra fotográfica de la estadounidense Cindy Sherman, la cual está conformada por retratos de la autora en varias poses y vestimentas. El trabajo más renombrado de Sherman es Untitles Film Stills (1977-1980), donde ella investiga los clichés cinematográficos a través de la figura de la mujer deseable. Cada "fotograma" de Untitles Film Stills imita tan bien las proyecciones del imaginario hollywoodiense clásico que parece realmente sacado de una película, y la modelo fotografiada (la misma Sherman) parece una star. Es sorprendente comprobar la semejanza entre algunas de estas fotos y las fotos de portada de los poemarios de González. La imagen que abre Gran Avenida se combina con la foto número 54 del libro de Sherman, donde la sujeto, peinada a la Marilyn Monroe, se encuentra de pie en medio de la calle: la luz violenta, la soledad y los indicios de un desenfreno recién vivido son los mismos. Los fotogramas 21 y 58 presentan analogías con la foto de Aire Quemado: la sujeto, retratada sobre un fondo de modernos edificios, mira ensimismada hacia afuera del encuadre. Sin embargo, el plano contrapicado (o enfoque desde abajo hacia arriba) le confiere una confianza en sí misma que le falta al grácil sujeto fotografiado de frente, y en un entorno que se desmorona, de Gladys González. 
Otro paralelismo entre la obra de González y Sherman consiste en que, en la evocación algo kitch-rétro del estrellato en la obra de esta última, un pequeño error de encuadre, un descuido en un elemento del escenario, una rigidez calculada en la pose, denuncian el artificio de la escena, generando una seducción del espectador que queda intencionalmente incompleta. La relación entre este último y el artista es interpretable, según la crítica Amelia Jones, bajo el concepto del quiasmo, en el cual "[...] while one subject sees another, the subject in seeing is also seen and so made flesh. [...] Sherman's work can be seen to encourage an opening of the viewer/artist relation such that the viewer (or, more accurately, participant) "turns inside out", experiencing her investments and desires relative to the figures enacted in Sherman's work." (33). De forma análoga, el lector de los poemarios de Gladys González no solamente proyecta sus fantasías voyeurísticas sobre la figura marginal que la autora construye, sino que, gracias a la grieta abierta por el cruce intermedial, accede a esta visualidad multiplicada mirándose actuar en ella. A pesar de ello, la propuesta de González no se limita a un escondite meta-conceptual con el lector. Con cierta anticipación y casi clarividencia con respecto a la difusión masiva de la comunidad virtual de Facebook, sus poemarios tematizan y vuelven palpable la angustia de una sujeto que escudriña el espacio alrededor suyo en busca de otra mirada que intercepte la suya, no necesariamente para establecer una conversación sino que para obtener el poke o el like como confirmación de que sigue en el foco de interés. La obsesiva visualidad que caracteriza los poemas de Gladys González es coherente con la exposición compulsiva -y sin destinatario específico- de la intimidad en esta red social. En este caso, la literatura se haría síntoma o portavoz de este nuevo despliegue de lo subjetivo y de lo afectivo; denunciaría que, como señala el estudioso Juan Martín Prada, "nos hallaríamos hoy en una evidente crisis de lo introspectivo, en un permanente intercambio de intimidades o en la espectacularización de la intimidad, que deviene "extimidad"." (48). A pesar de que según el fundador de Facebook Mark Zuckerberg el éxito de esta comunidad virtual se debe al hecho de que la identidad de la gente que entra en Facebook es real ${ }^{5}$, sabemos que las identidades reales recaen muy pronto

5 Cfr. Antonio Jiménez Barca en "Zuckerberg: "Las revoluciones populares no las hace Facebook", Ciberpaís [España] 25 de mayo de 2011: s.p. Web. 
en la pose, como lo demuestra el estilo de tomar fotos ligado al uso de esta red: las "selfies". En este contexto 2.0 la obra de González, con su dejo vintage, culto y descabellado, demuestra que la fusión entre ficción y verdad es el meollo de la filosofía de redes social como Facebook.

\section{Juan Carreño: a la escucha de las voces de la colectividad}

Si la poética de González puede ser vista como un anticipo del habitus socio-psicológico asociado con Facebook, la estética que caracteriza el primer poemario de Juan Carreño -y el corto que funciona como su contracara- es parecida a la de los videos grabados con celulares y subidos a You Tube o a plataformas similares. Por ejemplo, es posible encontrar en internet videos compartidos por los jóvenes que se enfrentan con la policía en comunas marginales de Santiago en ocasión del 11 de septiembre de cada año, fecha en que se conmemora el Golpe de Estado de 1973. Se trata de fragmentos de "realidad" expuestos y ofrecidos sin edición a los demás usuarios de la red. Esta práctica da cuenta tanto de una nueva forma de realismo digital como de la utilización de las posibilidades ofrecidas por Internet para que las comunidades o los agrupamientos transversales de personas den cuenta de su propia versión de los hechos, la cual puede diferir de la que se difunde en los medios controlados por las corporaciones. De manera análoga, las obras Compro Fierro (2008) y Santo Tomás: entre Bahía Catalina y La Serena, entre la Iglesia y loh pacoh (2011) de Juan Carreño se construyen a partir de una retórica y una ideología común: el intento de reproducir fielmente la vida cotidiana de un barrio de La Pintana a través de las voces de sus habitantes y, especialmente en el caso del poemario, aparentemente sin edición. Las escenas de ternura y abandono, degradación y fatalismo, frustración y alegre barullo de esta comuna de bajos recursos de la zona sur de Santiago se manifiestan, antes que nada, a nivel auditivo. La mediación de la instancia creadora es deliberadamente mantenida al mínimo, para que la colectividad con sus expresiones vocales tome cuerpo y protagonismo empoderándose desde lo vivencial y estético. En este caso, la intermedialidad se puede atribuir a una práctica y visibilización de la interpersonalidad (López-Varela Azarcate 2011), en cuanto fundamento cognitivo y afectivo de las nuevas formas de comunicación que necesariamente mezclan modos y medios diversos. En otras palabras, en nuestra época de conectividad abarcadora 
y constante, el sujeto es tal porque se relaciona con los demás. Podríamos plantear que la propuesta de Carreño, por medio de su intermedialidad y de su apertura a las diferentes voces de la comunidad, actualiza al nuevo milenio el concepto deleuziano de "dispositivo colectivo de enunciación": en la literatura menor postulada por Deleuze y Guattari no se da enunciación individualizada, atribuible a un único autor, sino que la enunciación se hace necesariamente colectiva, apropiable por cualquiera (1975).

Como ya he anticipado, Compro Fierro en tanto palabra poética se origina, en buena parte, en una práctica que pertenece a otro campo medial: el registro sonoro. El poeta recorría las calles de su barrio con una grabadora, para capturar las voces de los vecinos. Luego transcribía las partes de los diálogos que le parecían interesantes. En un primer momento, su trabajo consistió casi enteramente en recolección y edición de material. A esta parte más bien etnográfica (hay que recordar que en los años de composición del libro el poeta estaba estudiando antropología), se le combinaba el pulimento poético posterior 6 . El resultado es una serie de poemas que arrastran el registro sonoro, con su particular transcripción fonética y el predominio de un léxico chileno popular, hacia el territorio de lo alucinante, donde la normalidad enseña su lado unheimlich. Un ejemplo de ello es el texto "El jugo del cuchillo de mayo" donde el locutor, con el cual posiblemente se identifica el poeta, acompaña a Julio Tutú en su loca carrera. Los dos, drogados con vapores de bencina aspirados en una botella, se lanzan en una búsqueda compulsiva de cuchillos en la feria y en el supermercado: "corriendo entre pescaderías vacías / el Julio Tutú repetía / Esto no puee ser así / Esto no puee ser así / en una paró la calle / trahpirao gritó a los abogados y marinos / ustedes no saben / ustedes no saben ni una gueá / calmao Julio, le decía / que tenemo que encontrar loh cuchillos..." (69). En el final del poema, los personajes hablan de heces y orinan frente a los paseantes. El autor indaga aquí un aspecto de la marginalidad como la dependencia de las drogas a través de sus delirantes efectos (trastornos mentales y conductas inapropiadas) al límite de lo cómico y de lo escatológico ${ }^{7}$, en lugar de interrogar sus causas con actitud compasiva y paternalista. Además,

Comunicación personal con el autor, Marzo 2013.

Lo escatológico se refiere a las deyecciones corporales. 
como lo demuestra este fragmento, la lengua oral resulta escarbada en su pobreza, en su sobriedad de palabra pronunciada y destinada a desaparecer inmediatamente, sin dejar rastro. El habla de la comunidad, desnudada tal como se da, no se resuelve en goce sonoro para el lector: la materialidad del habla es disecada hasta el esqueleto de fonos y fonemas. La reproducción de la fonética y la fonemática ${ }^{8}$ de ese sociolecto es el elemento crucial de la operación poética de Carreño, desde un punto de vista tanto poético como ideológico. Los poemas no constituyen un documento de interés etnológico en los que se aplican las convenciones de la transcripción vigentes en sociolingüística, sino por el contrario, son un esfuerzo por elaborar la versión escrita de una lengua oral, lo que supone la selección, según reglas autónomamente determinadas, de fonemas que representen determinados fonos. Véase el siguiente fragmento como ejemplo: “...Pato / oye oye / yo te conohco / me acmira / si pa qué/ pa qué / te regalo una chaqueta si querí / mira que soy bacán / se ehtán cagando e la risa e vo Pato / compremo una cerveza mejor." (31). Como podemos notar, ha habido una sustitución de determinados fonemas con otros más pertinentes ("conohco" por "conozco") y una tachadura de los fonos que no se pronuncian ("e la risa" por "de la risa", "compremo" por "compremos"). El lector no se mide entonces con un significante puro, con sonidos capturados y reproducidos como una sintomatología, sino con un idioma en sus derechos, diferente y similar a la vez a la lengua vehicular y referencial, un idioma que mantiene abierta la posibilidad de ser decodificado pero que, a la vez, se rige por sus propias reglas. En su esfuerzo por transferir a la escritura una lengua que vive en la oralidad y en el margen, Juan Carreño realiza una interesante operación de re-posicionamiento de la lengua de la norma con respecto a estas otras versiones del chileno, poniéndolas todas en el mismo nivel de dignidad y abriendo la comunicación desde las particularidades de cada una.

Por otra parte, el conjunto de fonemas que aparecen en las páginas puede ser considerado como "partitura" o fonotexto, a saber, la serie de indicadores que alude a la realización oral de la escritura. El fonotexto, noción introducida por Garret Stewart, consiste en "subvocal

8 La escritura o transcripción fonética se refiere a los sonidos (fonos) en su pronunciación (sitio y modo de articulación), describiéndolos a través de símbolos convencionales (Alfabeto fonético internacional) entre paréntesis cuadrados. La escritura o transcripción fonémica se refiere, por el contrario, al fonema, o sea la unidad mínima, abstracta y diferenciadora de la lengua que sola o en conjunción con otras permite la atribución de un valor semántico, y se escribe entre barras oblicuas. 
enunciation running simutaneously across, and sometimes fractionally out of sync with, the scriptive phenotext" (239): una especie de voz entre las líneas, o de enjambre de sonidos que se reúne alrededor de las frases. La voz está siempre virtualmente presente en lo escrito: "subvocalization actualizes these possibilities in the body and makes them available for interpretation" (Hayles 74). La escritura no se limita, entonces, a ser mera transmisión de significados. Por el contrario, es el código gráfico que activa en la mente del lector las pronunciaciones y los tonos que la escucha atenta del poeta recogió en su momento. También en este caso, no es un goce des-responsabilizado de sonidos "típicos" lo que esta propuesta poética quiere generar en el lector, sino el acercamiento a un registro sonoro virtual a través del aprendizaje de sus reglas de activación. Véase el siguiente fragmento como ejemplo: "Pero anteh de too eso / que se noh salió derrepente / el Cesitar / noh llegaba vendiendo la leche / que le daban en el consultorio / entero ya palomo noh decía / que lah ehtrellas lo molehtaban..." (44). La sibilante interdental, que en la pronunciación chilena es aspirada en posición antecedente a consonante y al final de palabra, es sustituida aquí por un " $\mathrm{h}$ ", dictando, incluso en la lectura silenciosa, una correspondiente modificación en la posición de los órganos fonatorios. También desaparece la consonante intervocálica alveolar sonora en "todo", y la líquida se refuerza en el adverbio "de repente" hasta soldar las dos partes en una sola palabra.

Verificaré ahora cómo el fonotexto de los poemas se convierte en audiotexto en la pista audio del corto Santo Tomás. El término audiotexto ha sido acuñado por Charles Bernstein, y se refiere a "the audible acoustic text of the poem" (12) en la dimensión de la auralidad, o sea la recepción auditiva de la voz reproducida por medios analógicos o digitales. El audiotexto que me interesa investigar es el de las voces de unos niños que protagonizan el corto, y los ruidos y demás voces que los acompañan en sus andanzas por el barrio de Santo Tomás (La Pintana). El paisaje sonoro que ellos atraviesan, y al que contribuyen, se compone de sonido y ruidos de todos los días: los entrechoques de los pedestales y de las cajas de la feria al final del día; los discursos de los adultos; las pisadas y la respiración agitada de grupos de niños que juegan a la carrera; los sermones de los pastores evangélicos gritados por megáfono; el murmullo de un partido de fútbol emitido por la tele de un almacén. $\mathrm{Si}$, como acabo de postular, los poemas son a la vez versiones escritas 
de una lengua autónoma y partituras para la ejecución oral de las voces en ellos contenidas, los parlamentos que se escuchan en el corto son el audiotexto de poemas visuales hechos a partir de encuadres y montaje. En particular, es significativo cómo el Juan Carreño co-director elija separar, en la mayoría de los casos, la realización vocal de una frase -o sea su ejecución sonora- de su pronunciación efectiva por parte de los pequeños actores. Las voces quedan así recortadas de los labios que las emiten. Los parlamentos empiezan en los momentos en que la pantalla aparece vacía y negra, anticipando la imagen, o se dibujan sobre la cara seria o sonriente del niño que no está hablando.

De a poco, el espectador empieza a asociar correctamente la voz con la persona y a reconocerlas a partir de su timbre, su tono, su espesor. Además, como en el poemario, se puede comprobar un esfuerzo de transcribir la fonemática del habla y de crear de una lengua con características "propias": los subtítulos contienen escrituras como "pa yo buhcar", "aónde", "me insultáronme", "hohpital". Las voces en su materialidad y autonomía se vuelven así el eje alrededor del cual gira la obra audiovisual. Prueba de esto es el hecho de que, cuando uno de los niños acaricia al otro, el director elige hacer callar cualquier sonido con excepción de un liviano zumbido de fondo similar al de la cinta de una videocámara en grabación. Deja espacio, de esta forma, a un tipo diferente de comunicación, de voz, que es el gesto de cariño. Por otra parte, la banda sonora se limita a unas pocas notas tocadas en un xilófono, que aparecen de vez en cuando como el pulso rítmico de un poema, su escansión entre llenos y vacíos, entre verso y "aparte".

La impresión de que el poemario y el corto representan las dos caras de una misma medalla no se limita al guiño que el segundo hace al primero (en una escena, un chico lee parte del poema de Carreño "Poema escrito por más de cien jóvenes la noche del 11 de septiembre del 2005 en avenida Santo Tomás con La Serena, La Pintana" desde una fotocopia pegada en un poste, ahora en la noche del 11 de septiembre de 2011). Por el contrario, el efecto de interdependencia es producido por el cruce intermedial que el autor hace entre medios artísticos a partir de una misma problemática. La fidelidad a lo que su oído captura en su comuna de la periferia sur no se convierte en dos versiones separadas de un mismo original o en una traducción de una versión a otra, sino que en 
un ir y venir, un movimiento en la frontera entre dos medios: el poema escrito y el "poema" audiovisual.

\section{4. ¿Cuáles sujetos en cuál margen urbano?}

En un artículo de su libro Diferentes, desiguales y desconectados, García Canclini se pregunta: “¿Por qué el arte reciente está redescubriendo al sujeto o buscando recrearlo?" (23). Creo que las obras comentadas en este ensayo pueden proporcionar una respuesta tanto en relación con los sujetos representados (los marginales, los rebeldes), como con los sujetos lectores (posiblemente letrados y que no se consideran parte del margen). Por medio de la solicitación de diferentes sentidos, producida por el cruce intermedial, estos autores privilegian la corporeidad de los sujetos, a pesar de que la trabajan a través de sus manifestaciones más lábiles como la silueta de una pose o la voz de los vecinos del barrio. Ambos se adentran en unos pliegues orgánicos de la ciudad que el juego de extrañamiento en el engaño ficcional-biográfico o la diagramación fonemática de una lengua eminentemente oral vuelven menos obvios y más desafiantes para el lector. De esta exploración visual y auditiva de la materialidad del sujeto marginal deduzco dos formas en que esta figura es elaborada en el arte y se hace espejo que le devuelve al lector una nueva imagen de sí. Por una parte, en sintonía con la expansión de las redes sociales, el sujeto es percibido como intensidad del yo, un "yo expresivo", como postula González Prada, "un "yo" identitario que quiere hablar de sí mismo, de lo que hace, de lo que opina, de lo que quiere" (149): es el sujeto delineado por González, ícono legendario de una marginalidad rebelde y exclusiva. Por la otra, está la colectividad de sujetos de Carreño: similar a un enjambre o una bandada de voces, es análoga a "la multitud en línea" que, según Prada, "no se halla en esencia gobernada, nadie la representa, no hay contrato social en la multitud. [...] Su volatilidad, sin embargo, no se halla en contradicción con su fuerte carácter cooperante, que emerge de manera espontánea en el solapamiento y correspondencia de intereses, afinidades, tendencias y experiencias comunes" (69). El poeta ausculta los movimientos, las vocalizaciones y las frases de individuos no necesariamente reunidos en una comunidad homogénea y fuerte como antaño, sino esparcidos en potencialidad de encuentros e intercambios. Aunque la marginalidad que Carreño retrata es a menudo 
sinónimo de inmovilidad y fatalismo, la forma estética con que trabaja la predispone idealmente a estas posibilidades de mutación.

En relación con este último punto, es interesante ver cómo la representación del sujeto marginal y de situaciones de desigualdad en la ciudad pasa menos por una configuración ya acabada y consignada a la imaginación del público y más por un juego de desafío y colaboración in fieri con el lector, el otro polo de esta investigación perceptiva y corporal acerca del sujeto urbano. Gladys González provoca al lector poniéndolo en el lugar del voyeur y forzándolo a mirar el descalabro de una marginalidad elegida e impresa como una herida en un cuerpo sexuado, que el pacto ficcional ratificado por las fotos de portada y la mención textual del nombre propio atribuye a la autora en persona. Haciendo hincapié en las implicaciones libidinales de una mirada que busca en estas imágenes el desahogo, tanto de deseos de rebeldía frente al sistema, como de fantasías de dominación hacia una sujeto depotenciada, la obra enseña que la lógica de la abyección sigue afectando la construcción simbólica de la sociedad como sistema dividido en un centro y un margen. Al mismo tiempo, la verosimilitud de lo propuesto es arrastrada hacia la duda por medio de la insistencia en la pose: los deseos escapistas de vivencias vicarias en la marginalidad por parte del lector se ven reflejadas en un laberinto de espejos. Por otra parte, el esfuerzo de Juan Carreño de garantizarles a las hablas de su comuna la dignidad del acceso a la escritura, en el respeto de su fonética y de sus reglas de uso, implica que al lector también se le pida su disponibilidad para aprender un sistema lingüístico algo diferente, o sea para conocer al ciudadano de la comuna desfavorecida desde su estilo lingüístico y por ende desde su epistemología; en una palabra, a escuchar su voz y a empatizar con su calidez y ternura.

En conclusión, las obras de González y Carreño hacen dialogar a través de la intermedialidad el sujeto presentado en la página con el sujeto que a ella se asoma. En el primer caso, el lector es puesto cara a cara con su (posible) deseo de poner al sujeto marginal en un lugar de-potenciado, pero luego se queda atrapado junto con él en un mismo engaño óptico. En el segundo, el lector es invitado a visitar al sujeto marginal en su horizonte más propio que es su forma de expresarse, y por lo tanto a cuestionar, en este tránsito, su forma de entender la estructura social. Recorriendo estas dos sendas, el lector aprende a re-conocer su 
ciudad y las zonas "marginales" y a renombrarlas como una colectividad de individualidades, presente en verso, visión, escucha.

\section{Bibliografía}

Bernstein, Charles. "Introduction", en Charles Bernstein (ed.), Close Listening. Poetry and the performed word. New York: Oxford University Press, 1998. 3-28.

Butler, Judith. Bodies that matter. On the discursive limits of "sex". New York: Routledge, 1993.

García Canclini, Néstor. Diferentes, desiguales y desconectados. Mapas de interculturalidad. Barcelona: Gedisa, 2005.

Carreño, Juan. Compro fierro. Santiago: Balmaceda Arte Joven, 2010 [2007].

Santo Tomás: entre Bahía Catalina y La Serena, entre la Iglesia y loh pacoh. Santiago: FECISO, 2011.

Deleuze, Gilles y Félix Guattari. Kafka. Pour une littérature mineure. Paris: Les Éditions de Minuit, 1975

González, Gladys. Gran Avenida. Santiago: La Calabaza del Diablo, 2004. . Aire quemado. Cochabama: Yerba Mala cartonera, 2010 [2009].

González Barnet, Ernesto. “Gladys González: entrevista”. Letras.s5.com (2007): s.p. Web. 12 Oct. 2013.

Hayles, Catherine. "Voices out of Bodies, Bodies out of voices. Audiotape and the Production of Subjectivity". Soundstates: Innovative Poetics and Acoustical Technologies. Ed. Adelaide Morris. Chapel Hill: The University of North Carolina Press: 1997. 74-98.

Jones, Amelia. "Tracing the Subject with Cindy Sherman". Cindy Sherman. Retrospective. New York: Thames \& Hudson, 2000. 19-53.

López-Varela Azcárate, Asunción. "Génesis semiótica de la intermedialidad: fundamentos cognitivos y socio- 
constructivistas de la comunicación". Cuadernos de Información y Comunicación 16 (2011): 95-114.

Molloy, Silvia. "La política de la pose". Las culturas de fin de siglo en América Latina. Comp. Josefina Ludmer. Rosario: Beatriz Viterbo editora, 1994. 128-138.

Prada, Juan Martín. Prácticas artísticas e internet en la época de las redes sociales. Madrid: Akal, 2012.

Rajewsy, Irina. "Intermediality, Intertextuality, and Remediation: A Literary Perspective on Intermediality". Intermédialités, 6 (2005): 43-64.

Sherman, Cindy. Cindy Sherman: the Complete Untitled Film Still. New York: Museum of Modern Art, 2003.

Stewart, Garrett. Reading Voices: Literature and the Phonotext. Berkeley: University of California Press, 1990. 